\title{
Comparison of the Effect of Various Tobacco Habits on the Lipid Profile in a Population of Middle-aged Individuals: A Cross-sectional Analytical Study
}

\author{
${ }^{1}$ Anuja Shinge, ${ }^{2}$ Deepa Das, ${ }^{3}$ Bhakti Soman
}

\begin{abstract}
Background: There is now a worldwide epidemic of cardiovascular disease, atherosclerosis being the most common. Mostly the atherosclerotic-related diseases are acquired diseases. Tobacco is the most critical risk factor for atherosclerotic diseases which can be controlled and preventable. In this context,the aim of this study was to evaluate the consequences of chronic use of tobacco on the lipid profile of the middle-aged population.
\end{abstract}

Aim: Aim of the study was to evaluate the impact of various tobacco habits on the serum lipid profile.

\begin{abstract}
Materials and methods: Patients who attended the outpatient department (OPD) of Oral Medicine Diagnosis and Radiology (OMDR), screened randomly for habits of tobacco smoking and chewing, 45 patients were selected who had a habit of smoking and/or chewing tobacco, as a study group and 15 patients with no habits were chosen as the control group. Detailed information was taken regarding the frequency, duration, content of the form of tobacco they used. The patients were subjected to estimation of lipid profile. The values were recorded and statistically analyzed. Comparison of lipid profile and atherosclerotic index between tobacco smokers, tobacco chewers and nonsmokers/chewers were done using appropriate statistical analysis test. A p-value $<0.05$ was considered to be statistically significant.
\end{abstract}

Results: There was a significant increase in the total cholesterol (TC), low-density lipoprotein (LDL) and atherosclerotic index (Al) levels were observed in the tobacco users when we compared with nontobacco users. However, high-density lipoproteins (HDL) which is good cholesterol has a high level in nonusers compared to tobacco users

Conclusion: Increased levels of TC and LDL are the risk factors in the developing coronary heart disease. As tobacco is the known risk factor for atherosclerosis, extensive awareness is essential and can save the lives of many.

Keywords: Coronary artery disease, Lipid profile, Tobacco chewing, Tobacco smoking.

\footnotetext{
${ }^{1}$ Postgraduate Student, ${ }^{2}$ Professor and HOD, ${ }^{3}$ Senior Lecturer

${ }^{1-3}$ Department of Oral Medicine and Radiology, Y.M.T. Dental College and Hospital, Kharghar, Navi Mumbai, Maharashtra, India

Corresponding Author: Anuja Shinge, Postgraduate Student Department of Oral Medicine and Radiology, Y.M.T. Dental College and Hospital, Kharghar, Navi Mumbai, Maharashtra, India, Mobile: 9423868397, 9930040834, e-mail: anuja. shinge1891992@gmail.com
}

How to cite this article: Shinge A, Das D, Soman B. Comparison of the Effect of Various Tobacco Habits on the Lipid Profile in a Population of Middle-aged Individuals: A Cross-sectional Analytical Study. J Contemp Dent 2018;8(3):115-119.

\section{Source of support: Nil}

Conflict of interest: None

\section{INTRODUCTION}

In the 16th century tobacco was first introduced by Portuguese in India now India became one of the world's top consumers. The World Health Organization (WHO) has attributed 4 million tobacco-related deaths every year which will rise to 8.4 million by $2020 .^{1}$

The threshold level of $5 \mathrm{mg}$ of nicotine per day can be established and sustained addiction. ${ }^{2}$ People are aware that tobacco-induced cancer is the increasing cause of death. But they are least aware that tobacco can also cause death due to coronary artery disease. ${ }^{3}$

According to $\mathrm{WHO}$ coronary diseases will be the first cause of death in younger population in India by $2020 .{ }^{4}$

Coronary heart disease has been the well-known cause of death in atherosclerotic patients. As the habit of smoking and chewing tobacco has increased steadily among the younger and middle-aged population's awareness regarding the ill effects of tobacco is the need of the hour. The lipid profile and atherosclerotic index of a person show how vulnerable he is to develop atherosclerosis.

\section{Nicotine and Atherosclerosis}

Lipoprotein metabolism is an important factor in atherogenesis, which is the multifactorial process. Atherogenic index and lipoprotein ratios provide important information of metabolic and clinical profile of the atherosclerotic disease $^{5}$ (Flowchart 1). ${ }^{6}$

Nicotine is the active ingredient in tobacco. Nicotine stimulates adrenal medulla to release catecholamine. Catecholamines are the only hormones which effectively stimulates lipolysis in humans. Tobacco smoking and its effects on lipid profile have been proved by several studies. ${ }^{1}$ The main target of the therapies is the maintain the levels of LDL cholesterol concentration. Lipoprotein ration such as Total Cholesterol by HDL cholesterol and LDL by HDL cholesterol ratios has greater predictive 
Flowchart 1: Chart showing a possible mechanism by which nicotine absorbed from cigarette smoke may elevate plasma lipids and lipoproteins.

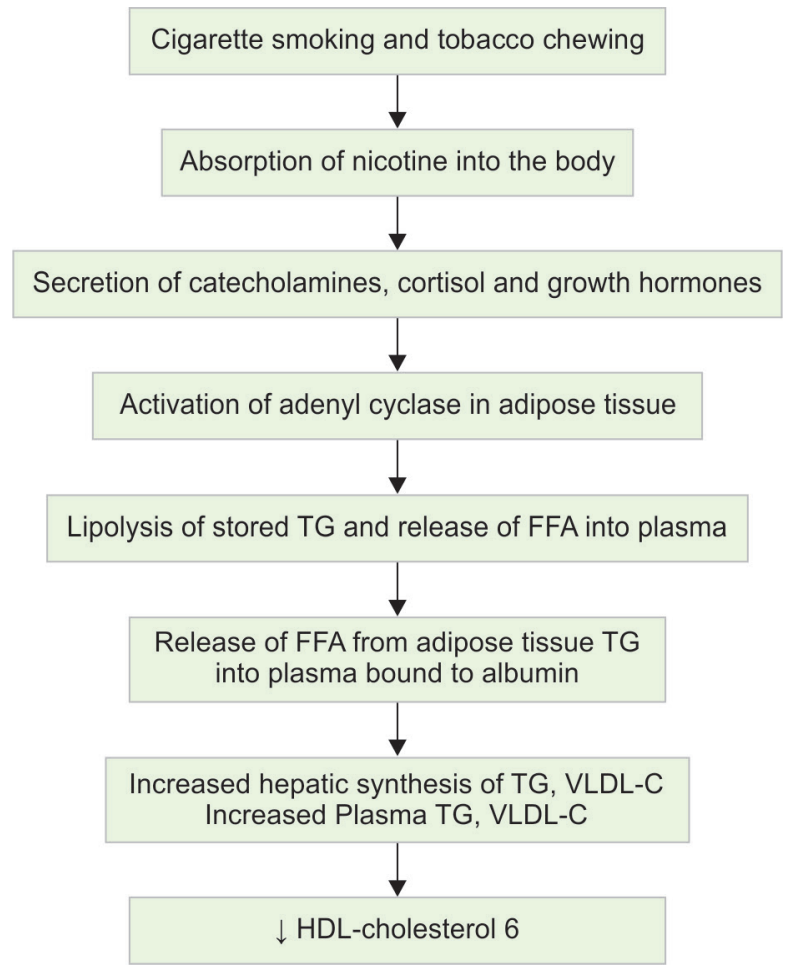

value for cardiovascular diseases than individual parameters. ${ }^{5}$ These ratios predict cardiovascular risk in the individuals. ${ }^{5}$ Very few studiesshowing the consequences of long-term tobacco chewing on lipid profile in Navi Mumbai population. Hence, this study was conducted to compare the impact of tobacco smoking, chewing and both on serum lipid profile in the subjects. The objectives were to evaluate serum lipid profile of people with a habit of tobacco smoking, tobacco chewing, people with a habit of both smoking and tobacco chewing and to compare the above results with the control group with no habit of using tobacco.

\section{MATERIALS AND METHODS}

The present study was carried out on 60 subjects in the age group ranging from 30 to 60 years. The age range of subjects were 30 to 60 years in the study. Study subjects were divided into four groups according to the type of tobacco habit. Each group constituted of 15 subjects. The subjects having the known systemic diseases such ashypertension, obesity, diabetes, lipid metabolism disorders, coronary artery diseases and the subjects on lipidlowering drugs and alcoholics were excluded. Subjects included in the study, who had the habit of chewing or smoking tobacco at least for 5 years and who agreed to participate and sign the consent form. The methodology of the study was described to the patient in his/her language. Ethical clearance was taken from the institutional ethics committee.
The study comprised of 4 groups:

Group-I: 15 subjects-Without tobacco habits

Group-II: 15 subjects-Tobacco chewers

Group-III: 15 subjects-Tobacco smokers

Group-IV: 15 subjects-Tobacco chewers and smokers.

The subjects were instructed to fast overnight before the day of investigation. Recording of the pulse, heart rate, and blood pressure was done when subjects were at rest. After the 14 hours of overnight fasting on the previous day $5 \mathrm{~mL}$ of blood samples were collected from the study individuals and sent to a laboratory for the estimation of serum lipid profiles. As shown in the table, readings were recorded. Using Zak technique estimation of total cholesterol was done where using Hantzsch condensation reaction levels of triglycerides were evaluated. Using Freidewald's formula levels of LDL and VLDL were calculated. For estimating HDL cholesterol precipitation of LDL, VLDL and chylomicrons were done by polyanions. Lipoprotein ratios and atherosclerotic indices were calculated based on formulas-

VLDL-cholesterol $=$ Triglyceride $/ 5$

LDL-cholesterol $=$ Total cholesterol-(VLDL-cholesterol + HDL-cholesterol)

Atherosclerotic index $=\mathrm{TC} / \mathrm{HDL}=\mathrm{LDL} / \mathrm{HDL}$

\section{STATISTICAL ANALYSIS}

Descriptive statistics were used to summarize the patient's demographics and survey responses. students "t" test was used for intragroup comparison where p-value $<0.05$ was considered to be statistically significant. All the values compared with the control group, i.e., nontobacco users. The study was of cross-sectional, analytical type.

\section{RESULTS}

The present study comprised of 15 people with no habits who were taken as control and 45 active tobacco consumers who fell in the age range of 48.53 years. Out of 60 patients $48(80.0 \%)$ were males and $12(20.0 \%)$ females. Male-to-female ratio was 3:1. Among 45 tobacco consumers, there were 15 smokers, 15 chewers and 15 with both the habits.

Significant variation was found in levels of total cholesterol, triglycerides, VLDL, LDL and atherosclerotic indices between the nontobaccousers and all tobacco users. Group IV smokers and chewers showed significantly higher values compared with nonusers (group I), alone tobacco chewers (group II) and tobacco smokers (group III). In contrast, the HDL-cholesterol showed higher values in nonsmokers and nonchewers (group I) compared with the remaining three groups and showed the least values in smokers and chewers (group IV). This may be due to the synergistic effect of long-term sustained blood nicotine values (Table 1 and Graphs 1 to 7). 
Comparison of the Effect of Various Tobacco Habits on the Lipid Profile

\begin{tabular}{|c|c|c|c|c|c|}
\hline $\begin{array}{l}\text { Sr. } \\
\text { No }\end{array}$ & Parameters & $\begin{array}{l}\text { Nonsmokers nonchewers } \\
\text { Group I }\end{array}$ & $\begin{array}{l}\text { Chewers } \\
\text { Group II }\end{array}$ & $\begin{array}{l}\text { Smokers } \\
\text { Group III }\end{array}$ & $\begin{array}{l}\text { Smokers and chewers } \\
\text { Group IV }\end{array}$ \\
\hline 1. & $\begin{array}{l}\text { Total cholesterol } \\
(\mathrm{mg} \%)\end{array}$ & $159.9 \pm 29.85$ & $\begin{array}{l}186.73 \pm 12.35 \\
p<0.0033\end{array}$ & $\begin{array}{l}219.6 \pm 25.78 \\
p<0.0001\end{array}$ & $\begin{array}{l}232.53 \pm 13.25 \\
p<0.0001\end{array}$ \\
\hline 2. & $\begin{array}{l}\text { Triglycerides } \\
(\mathrm{mg} \%)\end{array}$ & $101.36 \pm 38.25$ & $\begin{array}{l}147.13 \pm 33.81 \\
p<0.0017\end{array}$ & $\begin{array}{l}183.66 \pm 55.92 \\
p<0.0001\end{array}$ & $\begin{array}{l}186.46 \pm 35.45 \\
p<0.0001\end{array}$ \\
\hline 3. & $\begin{array}{l}\text { HDL-cholesterol } \\
(\mathrm{mg} \%)\end{array}$ & $71.86 \pm 15.76$ & $\begin{array}{l}55.93 \pm 15.86 \\
p<0.0101\end{array}$ & $\begin{array}{l}50.6 \pm 15.23 \\
p<0.0008\end{array}$ & $\begin{array}{l}46.06 \pm 8.03 \\
p<0.0001\end{array}$ \\
\hline 4. & $\begin{array}{l}\text { LDL-cholesterol } \\
(\mathrm{mg} \%)\end{array}$ & $91.68 \pm 26.01$ & $\begin{array}{l}138.80 \pm 40.52 \\
p<0.0007\end{array}$ & $\begin{array}{l}159.86 \pm 37.81 \\
p<0.0001\end{array}$ & $\begin{array}{l}178.6 \pm 24.97 \\
p<0.0001\end{array}$ \\
\hline 5. & $\begin{array}{l}\text { VLDL-cholesterol } \\
(\mathrm{mg} \%)\end{array}$ & $20.27 \pm 7.65$ & $\begin{array}{l}29.42 \pm 6.76 \\
p<0.0017\end{array}$ & $\begin{array}{l}36.73 \pm 11.28 \\
p<0.0001\end{array}$ & $\begin{array}{l}37.29 \pm 7.09 \\
p<0.0001\end{array}$ \\
\hline 6. & TC/HDL & $2.65 \pm 0.88$ & $\begin{array}{l}3.63 \pm 1.22 \\
p<0.0176\end{array}$ & $\begin{array}{l}4.69 \pm 1.48 \\
p<0.0001\end{array}$ & $\begin{array}{l}5.29 \pm 1 \\
p<0.0001\end{array}$ \\
\hline 7. & $\begin{array}{l}\text { Atherosclerotic } \\
\text { index (LDL/HDL) }\end{array}$ & $1.5 \pm 0.61$ & $\begin{array}{l}2.6 \pm 0.88 \\
p<0.0004\end{array}$ & $\begin{array}{l}3.4 \pm 1.21 \\
p<0.0001\end{array}$ & $\begin{array}{l}3.8 \pm 0.6 \\
p<0.0001\end{array}$ \\
\hline
\end{tabular}

SD: Standard deviation, SE: Standard error

The mean serum total cholesterol level was more by $59.64 \%(\mathrm{p}<0.001), 26.8 \%(\mathrm{p}<0.001)$ and $72.6 \%$ for subjects of groups II, III, and IV respectively. Mean serum VLDL level increase by $16.47 \%(\mathrm{p}<0.01)$ in group II and increased by $9.16 \%(\mathrm{p}<0.01)$ in group III while in group

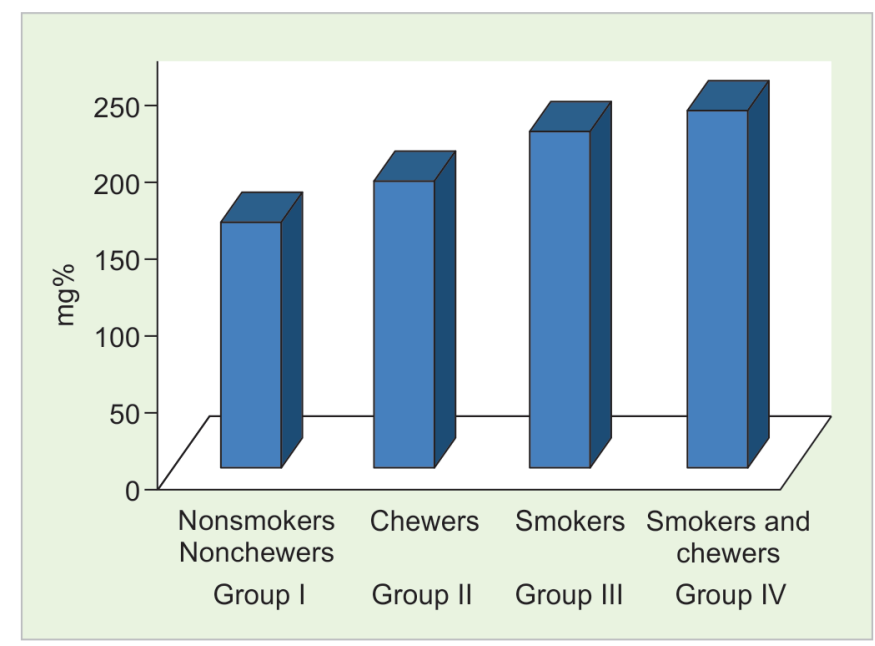

Graph 1: Comparison of mean serum total cholesterol values in all groups

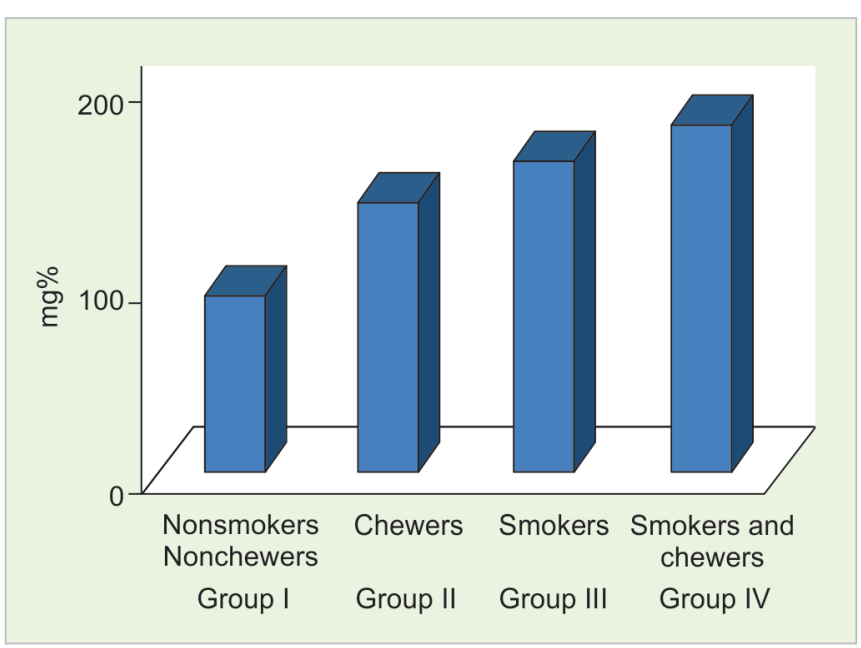

Graph 3: Comparison of mean serum LDL cholesterol values in all groups
IV it was increased by $17.03(\mathrm{p}<0.0001)$. The mean serum LDL level was increased about $68.37 \%(p<0.001)$ in subjects of group II, increased by $47.31 \%(\mathrm{p}<0.001)$ in group III, and in group IV increased by $87.11(\mathrm{p}<0.001)$. Whereas a decrease in mean serum HDL level in the

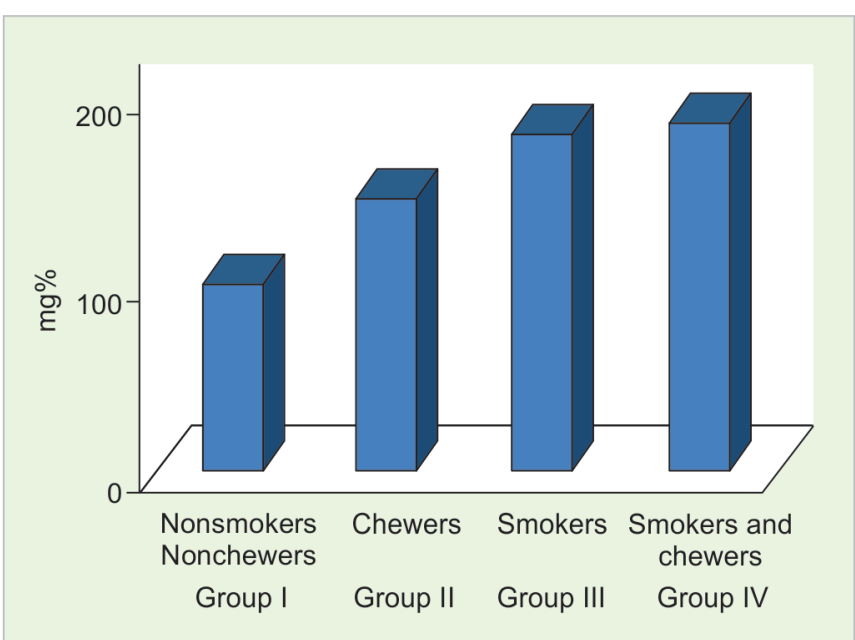

Graph 2: Comparison of mean serum triglycerides values in all groups

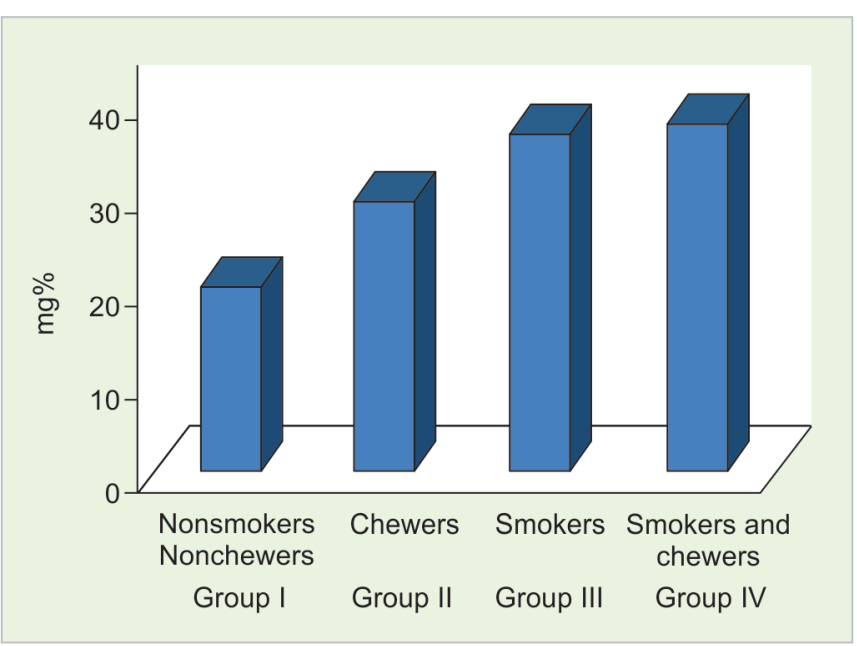

Graph 4: Comparison of mean serum VLDL cholesterol values in all groups 


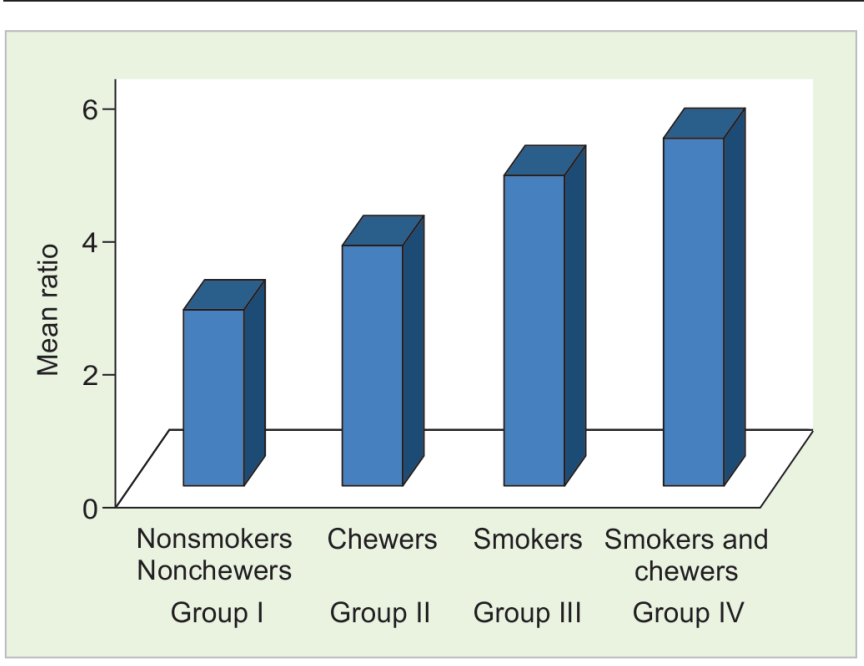

Graph 5: Comparison of TC/HDL ratio values in all groups

subjects of group II was $14.33 \%(\mathrm{p}<0.01)$ and in group III by $9 \%(p<0.001)$ and for group IV by 18.87 ( $<<0.001)$. The atherosclerotic index was increased of about $1.9 \%$ $(\mathrm{p}<0.001)$ in group II and by $1.1 \%(\mathrm{p}<0.001)$ in group III and in group IV by $2.3 \%(\mathrm{p}<0.0001)$.

\section{DISCUSSION}

According to Brischetto et al., ${ }^{7}$ in cigarette smokers blood high level of carbon monoxide damage the endothelium, facilitate the entry of cholesterol in the wall of the artery. Smoking affects the concentration of the plasma lipids and lipoproteins adversely. Relative anoxemia by the formation of carboxyhemoglobin in the tissues of the smokers including the myocardium. Platelet aggregation is facilitated by smoking. Nicotine from cigarette smoke may induce cardiac arrhythmias. In a habitual smoker, Nicotine enhances hormonal secretion of norepinephrine, epinephrine, growth hormone, and cortisolwhich occur 20 or more times a day. Activation of the adenyl cyclase of adipose tissue occurs which causes lipolysis of stored TG and free fatty acids flow into plasma. By binding to plasma albumin released free fatty acids (FFA) are transported to various tissues of the body which ultimately causesstimulation of hepatic TG and VLDL synthesis. In smokers, due to the effect of smoking the plasma free fatty acid level increases which decrease the plasma HDLc and increases plasma TG and $\mathrm{VLDL}^{8}$ risk of cardiovascular events are higher in smokers with low-tar cigarettes and smokeless tobacco in comparison to nonsmokers. ${ }^{9}$

Levels low-density lipoprotein and atherosclerotic index are the crucial levels in evaluating cardiovascular diseases. These ratios have a higher predictive capacity for determining cardiovascular diseases. ${ }^{5}$

In our study, it was observed that the mean LDL, VLDL, total cholesterol, triglycerides levels, and total triglyceride levels, atherosclerotic indices were high in those who used tobacco both smoking and smokeless

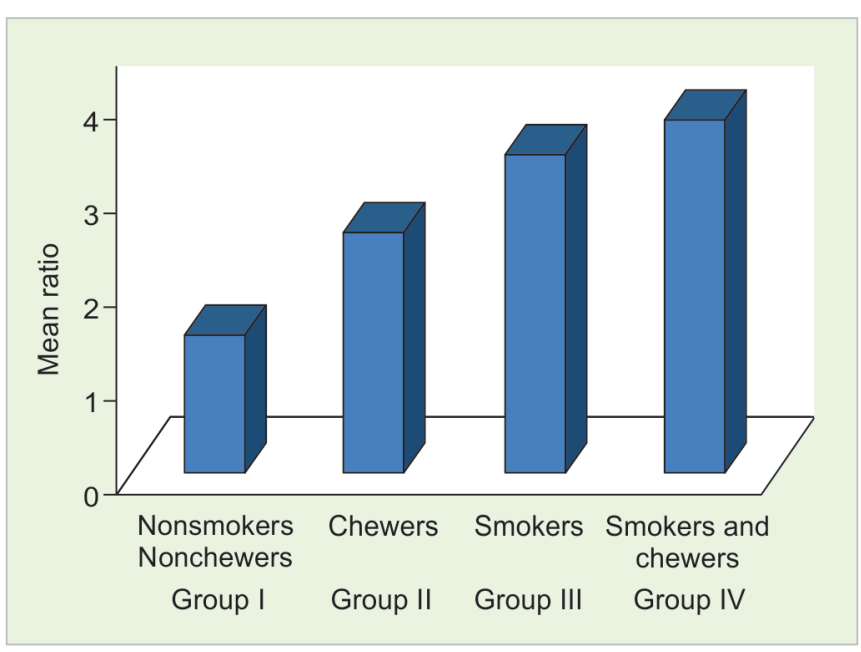

Graph 6: Comparison of atherosclerotic index in all groups

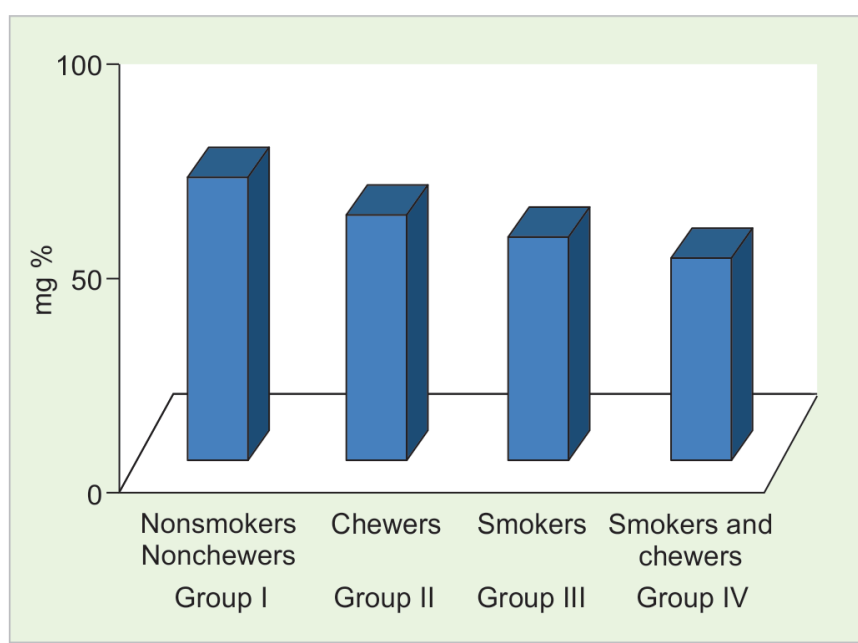

Graph 7: Comparison of mean serum HDL-cholesterol values in all groups

tobacco and their HDL levelswere low when compared to those who did not use tobacco.

Rao et al., ${ }^{4}$ also studied the variation of levels of lipid profiles in tobacco chewers and smokers having the habit for a longer duration. They observed that the HDL-cholesterol's levels were decreased and levels of $\mathrm{LDL}, \mathrm{TC}$, and triglycerides were increased in tobacco smokers and tobacco chewers group comparing with other groups which were concurrence with our study. Haragopal et al., ${ }^{1}$ studied the effects of chewing tobacco in serum lipid profile among the South Indian population. Authors observed that the significant difference in cholesterol values between non-users and long-term tobacco chewers which was similar to our observations. Neki ${ }^{10}$ Craig et al., ${ }^{11}$ Adedeji, ${ }^{12}$ Nagaraj et al., ${ }^{13}$ found decreased levels of HDL and Increase in the levels of LDL, VLDL, TG, TC in smokers in their study of the association between the lipid profile and chronic smoking. This was in similar to the findings of our study. Ahmed et al., ${ }^{14}$ observed similar results where there was raised levels of LDL, TG, VLDL and decreased levels of HDL in smokers 
and tobacco chewers, which was in agreement with the results of this study.

\section{CONCLUSION}

Our study emphasizes the strong relationship between abnormal of serum lipid levels and tobacco smoking, chewing. There was a statistically significant increase in lipid profile, atherosclerotic index and decrease HDL in those with habits of tobacco when compared to those with no habits. Increase in lipid profile, atherosclerotic index, and a decrease in HDL was critically significant in patients with both the habits when compared to smokers and chewers. This emphasizes the greater risk of developing atherosclerosis in the tobacco users compared to non-tobacco users. Tobacco has always been highlighted as a carcinogenic agent in an attempt to prevent its usage by the people. It is high time to create awareness that tobacco causes cardiac diseases too. So, the result of our study emphasizes the need for awareness that tobacco is not only a carcinogenic agent but also a risk factor for coronary artery disease (CAD) in the middle-aged population.

\section{REFERENCES}

1. Haragopal R, Aruna BM. Effects of Tobacco Chewing on Serum Lipid Profile in South Indian Population. International Journal of Scientific Study. 2016 Jul 1;4(4):9-11.

2. Reddy SS, Ali KS. Estimation of nicotine content in popular Indian brands of smoking and chewing tobacco products. Indian Journal of Dental Research. 2008 Apr 1;19(2):88.

3. World Health Organization, Research for International Tobacco Control. WHO report on the global tobacco epidemic, 2008: the MPOWER package. World Health Organization; 2008 Feb 11.
4. Ch SR. The effect of chronic tobacco smoking and chewing on the lipid profile. Journal of clinical and diagnostic research: JCDR. 2013 Jan;7(1):31.

5. Millán J, Pintó X, Muñoz A, Zúñiga M, Rubiés-Prat J, Pallardo LF. Lipoprotein ratios: physiological significance and clinical usefulness in cardiovascular prevention. Vascular health and risk management. 2009;5:757.

6. Devaranavadgi BB, Aski BS, Kashinath RT, Hundekari IA. Effect of cigarette smoking on blood lipids-A study in Belgaum, Northern Karnataka, India. Global Journal of Medical Research. 2012;12(6):57-60.

7. Brischetto CS, Connor WE, Connor SL, Matarazzo JD. Plasma lipid and lipoprotein profiles of cigarette smokers from randomly selected families: enhancement of hyperlipidemia and depression of high-density lipoprotein. The American journal of cardiology. 1983 Oct 1;52(7):675-680.

8. Gadpal RR, Deshpande KA, Waghmare MH. A Study of Lipid Profile in Tobacco Chewers and Smokers. J Contemp Med Dent. 2015;3:39-43.

9. Ambrose JA, Barua RS. The pathophysiology of cigarette smoking and cardiovascular disease: an update. Journal of the American college of cardiology. 2004 May 19;43(10):17311737.

10. Neki NS. Lipid profile in chronic smokers-A clinical study. Journal, Indian Academy of Clinical Medicine. 2002 Jan;3(1):51-54.

11. Craig WY, Palomaki GE, Haddow JE. Cigarette smoking and serum lipid and lipoprotein concentrations: an analysis of published data. BMJ. 1989 Mar 25;298(6676):784-788.

12. Adedeji OA, Etukudo MH. Lipid profile of cigarette smokers in Calabar municipality. Pakistan journal of nutrition. 2006;5(3):327-328.

13. Nagaraj PM. Effect of Cigarette Smoking on Lipid Profile. Journal of Biomedical and Pharmaceutical Research. 2014 Jun $28 ; 3(3)$.

14. Ahmed QR, Gupta N, Goyal S, Ansari SJ. Comparative study on lipid profile in tobacco chewers and nontobacco chewers. Natl J Physiol Pharm Pharmacol. 2015 Jan 2;5(2):142-144. 